reductions is being prepared. The preparation for press of the "Cape Photographic Catalogue", zones $-56^{\circ}$ to $-60^{\circ}$ and $-60^{\circ}$ to $-64^{\circ}$, has been completed ; astrometric work on the zone $-64^{\circ}$ to $-68^{\circ}$ was completed in $\mathbf{1 9 5 5}$ and the photometric work for this zone is almost finished. Position measurement for 4,400 stars in the $-68^{\circ}$ to $-72^{\circ}$ zone was com pleted, and proper motion and magnitude measurements are in progrsss. Preliminary work has been undertaken in all the remaining zones to the south celestial pole, involving 9,500 stars in all. A large programme of photoelectric photometry is under way with several telescopes. Magnitudes are being determined for many standard stars, stars on radial velocity programmes, parallax stars, stars in selected areas, comparison stars for cepheid variables, southern stars in the "Yale Bright Star Catalogue", and for other interesting objects. More than 7,000 observations were made during the year; more than 50,000 images were measured in a programme of photographic photometry, and other routine observations of the Sun, variable stars and occultations were continued. The radial velocity work at the Radcliffe Observatory was concerned with nearby stars, stars in the southern galactic cap and standard stars. Some miscellaneous observations were made on extragalactic nebulae, and the first section of the "Cape Photographic Atlas of Southern Galaxies" was published during the year.

\section{Society of Protozoologists}

THE following elections have recently been made by the Society of Protozoologists : President, Dr. Elery R. Becker (Arizona State College); VicePresident, Dr. Norman D. Levine (University of Illinois) ; Secretary, Dr. John O. Corliss (University of Illinois); Treasurer (retained), Dr. Daniel M. Lilly (St. John's University, Jamaica, New York) : Editor and Acting Editor of the Journal of Protozoology (both retained), Dr. William Trager (Rockefeller Institute) and Dr. Seymour H. Hutner (Haskins Laboratories, New York City) ; Honorary Member, Dr. Emmanuel Fauré-Fremiet (Collège de France, Paris). The Society will hold its next annual meeting with the American Institute of Biological Sciences in August 1959 at Pennsylvania State University.

\section{The Night Sky in November}

NEW moon occurs on Nov. 11d. 06h. 34m. U.T., and full moon on Nov. $26 \mathrm{~d}$. $10 \mathrm{~h}$. $16 \mathrm{~m}$. The following conjunctions with the Moon take place : Nov. 13d. l6h., Saturn $4^{\circ}$ S. ; Nov. 25d. 07h., Mars $3^{\circ}$ N. In addition to these conjunctions with the Moon, Mercury is in conjunction with Antares on Nov. 11 d. $12 \mathrm{~h}$., Mercury being $2 \cdot 1^{\circ} \mathrm{N}$. Mercury and Venus are too close to the Sun for observation. Mars rises at $17 \mathrm{~h} .25 \mathrm{~m} ., 16 \mathrm{~h} .05 \mathrm{~m}$. and $14 \mathrm{~h} .45 \mathrm{~m}$. at the beginning, middle and end of the month, respectively, setting on these dates at $8 \mathrm{~h} .55 \mathrm{~m} ., 7 \mathrm{~h} .30 \mathrm{~m}$. and $6 \mathrm{~h} .10 \mathrm{~m}$.; conditions for observation are very favourable. Mars reaches opposition on November 16, when its distance is 46 million miles and its stellar magnitude $-2 \cdot 0$. Mars continues to retrograde, moving from Taurus into Aries on November 22. Jupiter is too close to the Sun for observation. Saturn may be visible low in the south-west after sunset, but conditions for observation are not favourable. Occultations brighter than magnitude 6 are as follows, observations being made at Greenwich : Nov. 2d. 02h. 17.1m., 26 Gem. $(R)$; Nov. 3d.01h. 43.4m., 68 Gem. $(R)$; Nov. $27 \mathrm{~d}$. 20h. 58.6m., 115 Tau. $(R)$; Nov. $29 \mathrm{~d}$. 23h. 05.0m., $\lambda$ Gem. $(D)$; Nov. 30d. 00h. 17.9m., $\lambda$ Gem. $(R)$. $R$ and $D$ refer to reappearance and disappearance, respectively. The Taurid meteors are active during the first fortnight of the month, conditions being favourable; the radiant is near R.A. 3h. $36 \mathrm{~m}$., Dec. $+14^{\circ}$. The Leonid meteors are active on November 15-17, conditions being favourable; the radiant is near R.A. $10 \mathrm{~h} .08 \mathrm{~m}$. , Dec. $+22^{\circ}$.

\section{Announcements}

Mr. W. A. Dutron, assistant director of the Hosiery and Allied 'Trades' Research Association, Nottingham, and Mr. H. Marsden, Universal Winding Co., Ltd., Manchester, have been awarded the Institute Medal of the Textile Institute. This Medal was inaugurated in 1921 as an award by which recognition could be given for distinguished service to the textile industry in general and to the Institute in particular.

Trinity College, Cambridge, offers entrance exhibitions to male students of universities in the British Commonwealth to enable them to read for the degree of B.A., or LL.B., or for a diploma. Further information can be obtained from the Senior Tutor, Trinity College, Cambridge.

A CONFEREnce on Electronic Digital Computers and their Industrial Applications will be held in the Department of Mathematics, Birmingham College of Technology, on December 10, when members of IBM, Ltd., will speak on the following topies : data processing machines available; commercial applications on IBM 650 ; technical applications including linear programming; organization and preparation for electronic data processing. During the course of the day, three $16 \cdot \mathrm{mm}$. sound films to illustrate IBM machines will be shown. The conference fee is $£ 2$, and further details and application forms can be had from the Registrar, College of Technology, Gosta Green, Birmingham 4.

The Faraday Society Bourke Lectures will be delivered by Prof. R. H. Stokes (University of New England, Australia). The lectures will be: "Tracer Diffusion and Self-diffusion in Concentrated Electrolytes", in the Main Lecture Theatre, Chemistry Department, King's College, Newcastle on Tyne, on November 14, at 5.30 p.m. (chairman : Prof. W. F. K. Wynne-Jones); and "The Relation between Ion Mobility and Viscosity in Aqueous Solutions", in the Chemistry Department, University of Glasgow, on November 18, at 4 p.m. (chairman : Prof. J. Monteath Robertson). The second lecture will also be given at the Edward Davies Chemical Laboratories, University College of Wales, Aberystwyth, on November 20, at 5.15 p.m. (chairman: Prof. C. W. Davies). Further information can be obtained from the Faraday Society, 6 Gray's Inn Square, London, W.C.l.

WE regret that in referring to the appointment of Sir Rudolph Peters as president of the International Council of Scientific Unions (Nature, October 11, p. 990), he was wrongly described as lately director of the Agricultural Research Council Institute of Animal Physiology ; Sir Rudolph is, in fact, head of the Biochemistry Department of the Institute.

Erratum. In the communication entitled "Stability of Evaporated Films", by M. Wyn Roberts, in Nature of October 25, p. 1151, par. 4, line 11, for " $33 \times 10^{-3} \mathrm{~cm}^{3}$ (s.T.P.)" read " $13 \times 10^{-3} \mathrm{~cm}^{3}$ (S.T.P.)". 